\title{
Correction to: Can we differentiate neoplastic and non-neoplastic spontaneous adrenal bleeding? Imaging findings with radiopathologic correlation
}

\author{
Ali Devrim Karaosmanoglu ${ }^{1} \cdot$ Aycan Uysal $^{2}$ - Sevtap Arslan ${ }^{1} \cdot$ Cenk Sokmensuer ${ }^{3}$. Can Berk Leblebici ${ }^{3}$. \\ Deniz Akata ${ }^{1} \cdot$ Mustafa Nasuh Ozmen $^{1} \cdot$ Musturay Karcaaltincaba ${ }^{1}$
}

Published online: 26 November 2020

(c) Springer Science+Business Media, LLC, part of Springer Nature 2020

\section{Correction to: Abdominal Radiology https://doi.org/10.1007/s00261-020-02750-w}

The original version of this article contained a mistake in the co-author name "Canberk Leblebici". The correct co-author name should read as "Can Berk Leblebici". The original article has been corrected.

Publisher's Note Springer Nature remains neutral with regard to jurisdictional claims in published maps and institutional affiliations.

The original article can be found online at https://doi.org/10.1007/ s00261-020-02750-w.

Ali Devrim Karaosmanoglu alidevrim76@yahoo.com

1 Department of Radiology, Hacettepe University School of Medicine, 06100 Ankara, Turkey

2 Department of Radiology, Gulhane Training and Research Hospital, 06010 Ankara, Turkey

3 Department of Pathology, Hacettepe University School of Medicine, 06100 Ankara, Turkey 